
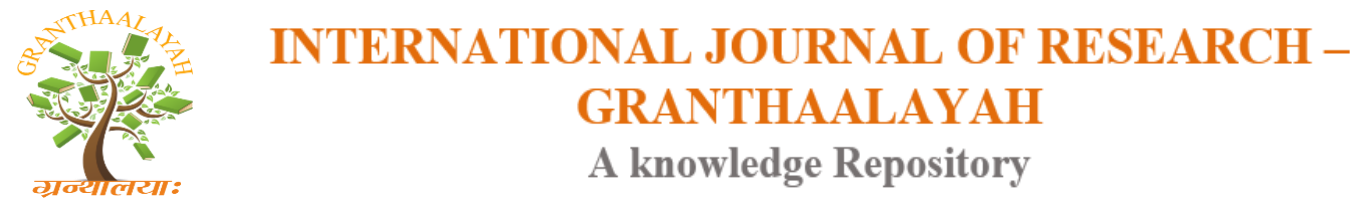

Science

\title{
STUDY AND PERFORMANCE TESTING OF TRANSISTOR WITH COMMON EMITTER AMPLIFIER CIRCUIT
}

\author{
Prof. G.R.Kumrey ${ }^{1}$, Dr. S. K. Mahobia ${ }^{2}$ \\ ${ }^{1}$ Assistant Professor, Department of Electrical Engg., Rewa Engineering College, Rewa (M.P.), \\ INDIA \\ ${ }^{2}$ Assistant Professor, Department of Physics, Rewa Engineering College, Rewa (M.P.), INDIA \\ DOI: https://doi.org/10.29121/granthaalayah.v4.i8.2016.2567
}

\section{ABSTRACT}

The transistor has ranking in 20th century technology. It is finding the application in all electronic devices as radios, computers. Integrated circuits are containing various transistors, which are made by silicon. The transistors are used to handle large current and/or large voltages. As example, the final audio stage in the stereo system used a power transistors amplifier to drive the various speakers. Transistors are device, which are utilizes a change in current to produce a large change in voltage, current, or power.

Keywords:

primary winding turns, secondary winding turns, transformer core.

Cite This Article: Prof. G.R. Kumrey, and Dr. S. K. Mahobia, "STUDY AND PERFORMANCE TESTING OF TRANSISTOR WITH COMMON EMITTER AMPLIFIER CIRCUIT" International Journal of Research - Granthaalayah, Vol. 4, No. 8 (2016): 100-103.

\section{INTRODUCTION}

There are two type of transistor which are used in power electronics devices.

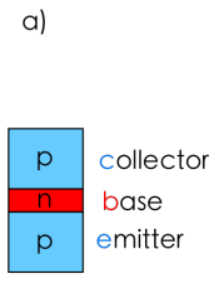

b)
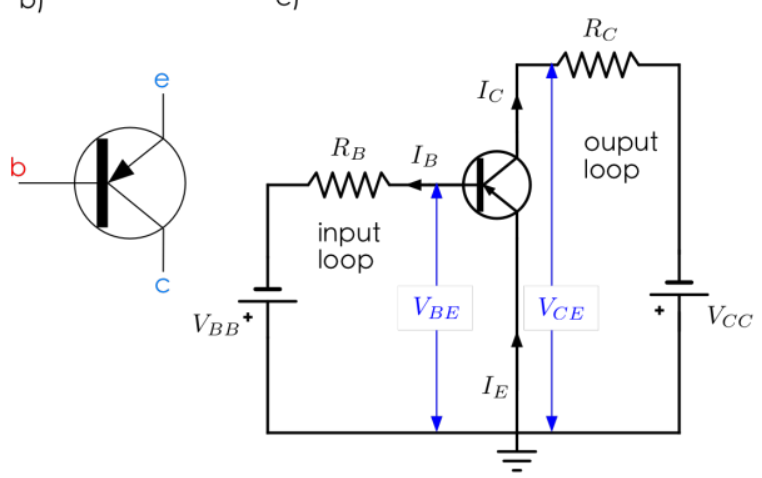

Figure 1: a) The schematics diagram of PNP Transistor
b) Circuit symbol
c) common emitter circuit 
The PNP transistors are shown in figure. These are consisting of a p-type emitter, an n-type base and a p-type collector, which are together form two PN junctions. In this amplifier circuit, voltages are supplied, so that the emitter base junctions are forward-biased and the collector base junction is reverse-biased. This means $\mathrm{V}_{\mathrm{CE}}>\mathrm{V}_{\mathrm{BE}}$. Common emitter circuit, so called because the emitter is common to the input circuit on the left and the output circuit on the right.

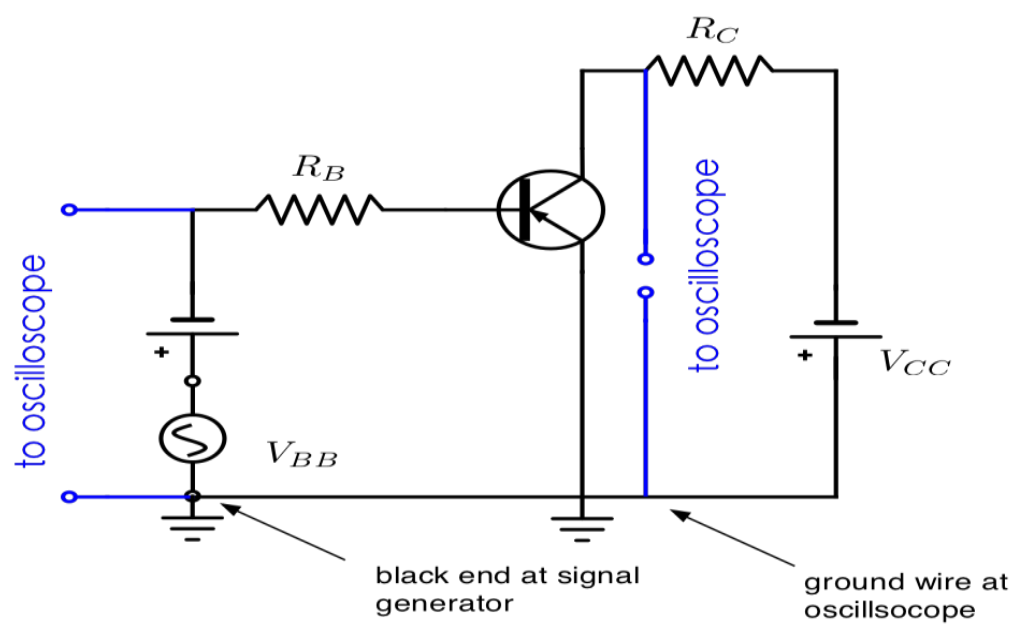

Figure 2: AC amplifier circuit

Consider the first of the entire forward-biased emitter-base junction. It is also very narrow $(<1$ $\mu \mathrm{m})$ making it easy for a large fraction, $\alpha$, of the holes to diffuse across to the collector-base junction where the junction voltage accelerates them into the collector region to form the collector current, $\mathrm{I}_{\mathrm{C}}$.

Thus, $\mathrm{I}_{\mathrm{C}}=\alpha \mathrm{I}_{\mathrm{E}}$

The remaining fraction, $(1-\alpha)$, of holes leave the base through the external connection to form the base current, $\mathrm{I}_{\mathrm{B}}$, where

$\mathrm{I}_{\mathrm{B}}=(1-\alpha) \mathrm{I}_{\mathrm{E}}$

The "current gain", $\beta$, of the transistor are defined by

$\beta=\mathrm{I}_{\mathrm{C}} / \mathrm{I}_{\mathrm{B}}$

$=\alpha /(1-\alpha)$

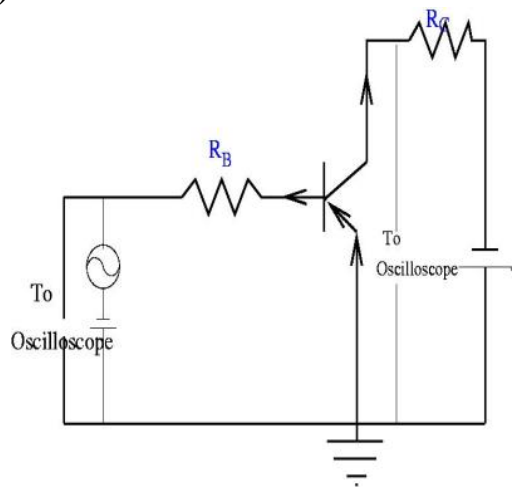

Figure 3: a) AC amplifier

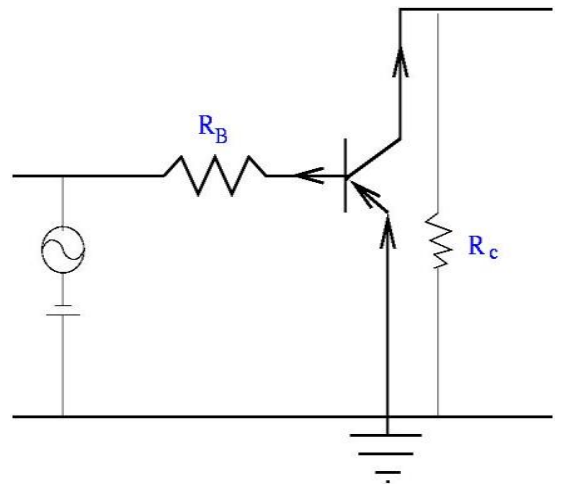

b) equivalent circuit 
Figure are shows the transistor used as an AC amplifier to amplify a small signal from a signal generator. Now the two batteries in the circuit behave like large capacitors with impedances $(1 / \omega \mathrm{C}) \sim 0$, so that the equivalent circuit is as shown in figure. The voltage gains are given by equation. However, these are a simplified situation.

\section{PROCEDURE}

The power supply outputs for the voltages $\mathrm{V}_{\mathrm{BB}}$ and $\mathrm{V}_{\mathrm{CC}}$. The symbols $\mathrm{e}, \mathrm{b}$ and $\mathrm{c}$ denoting the transistor connections. Use a $3000 \Omega$ resistor for $R_{B}$ and a $220 \Omega$ resistor for $R_{C}$. Turn the supply outputs to zero then turn on the unit. Set one of the digital meters to the $20 \mathrm{~V}$ DC range and connect it to measure $\mathrm{V}_{\mathrm{CC}}$ (+ lead to ground on the transistor board). Adjust $\mathrm{V}_{\mathrm{CC}}$ to approximately $15 \mathrm{~V}$. Reconnect the meter to measure $\mathrm{V}_{\mathrm{CE}}$. This should also read $15 \mathrm{~V}$, indicating $\mathrm{I}_{\mathrm{C}}=0$. Connect the second meter to measure $\mathrm{V}_{\mathrm{BB}}$, also with the + lead to ground. Slowly increase $\mathrm{V}_{\mathrm{BB}}$ up to $2 \mathrm{~V}$ and note $\mathrm{V}_{\mathrm{CE}}$ decreasing, indicating an increasing $\mathrm{I}_{\mathrm{C}}$. Your amplifier is now working.

\section{TRANSISTOR AS A SWITCH}

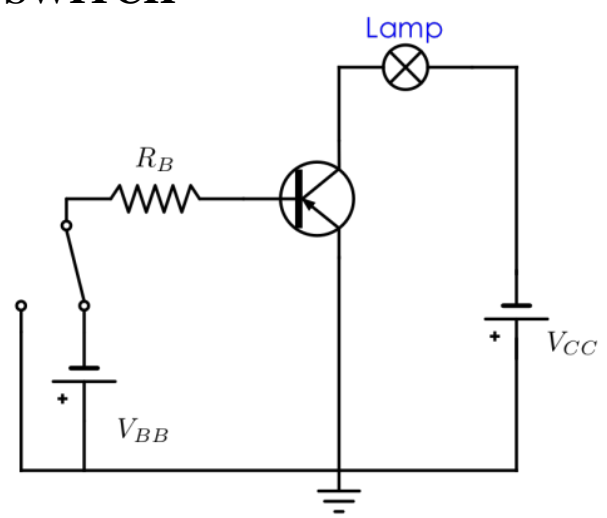

Figure 4: the transistor as a switch

\section{AC AMPLIFIER}

Increase $\mathrm{V}_{\mathrm{CC}}$ to $15 \mathrm{~V}$ and turn $\mathrm{V}_{\mathrm{BB}}$ down to zero. Increase $\mathrm{V}_{\mathrm{BB}}$ until $\mathrm{V}_{\mathrm{CE}}=7.5 \mathrm{~V}$. Connect the signal generator in series with $\mathrm{V}_{\mathrm{BB}}$ and adjust it to $100 \mathrm{~Hz}$. the black leads to ground on the transistor board for both connections. Observe the input and output waveforms. Note that adjusting $\mathrm{V}_{\mathrm{BB}}$ causes distortion of the output waveform. From the ratio of peak-to-peak voltages, determine $A_{V}$ for frequencies of $100 \mathrm{~Hz}, 1 \mathrm{kHz}, 10 \mathrm{kHz}$ and $20 \mathrm{kHz}$

\section{REFERENCES}

[1] Electrical Science” by J. B. Gupta

[2] A Text book of Electrical Technology" by B. L. Thereja Vol-11

[3] Electrical Engineering Fundamentals" by Del Toro

[4] Electric Circuits" by James Nelson (Pearson publication)

[5] Basic Electrical Engg." By DC Kulshreshtha, TMHill.

[6] Malcom Goodge, "Semiconductor Device Technology'", prentice - Hall, Inc., 1983.

[7] Tomas L. Floyd, "Electreonic Devices", prentice - Hall, Inc., 1996. 
[8] Henry B.Weisbecker, "Solid State Devices and Integrated Circuits ", Reston and prenticHall Company Inc., 1982.

[9] Neil Storey, " Electronics Systems Approach ", Addison Wesley publishing company Inc., 1992.

[10] E.Simoen, " Radiation Effects in Advanced Semiconductor Materials and Devices ", Springer-Verlay Berlin Heidelberg Inc., 2002

[11] The Gamma Cell 220 Excel Co 60 Irradiation Facility, "Nordion, Canada", catalog, 2002.

[12] Agilent Gillent 4155B/4156B "Simeconductor Parameter Analyzer" User's Guide Measurement and analysis Agilent part No. 04156-90200 catalog, 2000.

[13] Ugur Cilingiroglu, "Systematic Analysis of Bipolar and MOS Transistor", Artech House Inc., 1993. 